\title{
Nosocomial Outbreak of Pantoea agglomerans in a Pediatric Urgent Care Center
}

Eliana L. Bicudo ${ }^{1}$, Vanise O. Macedo ${ }^{2}$, Marlene A. Carrara ${ }^{1}$, Fabíola F.S. Castro ${ }^{3}$ and Ruth I. Rage ${ }^{3}$ ${ }^{1}$ SCIH of Santa Lúcia Hospital; ${ }^{2}$ University of Brasília; ${ }^{3}$ Laboratory Exame; Brasília, DF, Brazil

\begin{abstract}
Pantoea agglomerans is a Gram-negative bacterium whose isolates can be found in blood cultures and other secretions. This article described one outbreak of sepsis due to this bacterium in the pediatric urgent care center of a tertiary hospital, in Brasilia, Federal District. This was a case-control study and it evaluated the risk factors for acquisition of nosocomial sepsis caused by Pantoea agglomerans. Six case-patients and 15 control-patients have been found. The risk factors were: vomiting in the internment and presence of solution compositions in the intravenous hydration therapy received in bigger number than 2 compositions. The transference tube used for the compositions was contaminated with Pantoea agglomerans, characterizing the outbreak with common source. The evolution of all the patients was favorable.
\end{abstract}

Key-Words: Pantoea agglomerans, pediatric, nosocomial outbreak.

Pantoea agglomerans is a bacterium of the family Enterobacteriacea and it is a Gram-negative bacillus [1].

Pantoea agglomerans can cause disease in rare instances. It was found in wounds [2,3], blood and urine, as opportunistic pathogen [4].

Pantoea agglomerans, commonly found in plants, soil, water and food stuffs, although rarely recognized as an agent of endogenous nosocomial infections [5-7], can cause epidemics among hospitalized patients when associated with the use of contaminated intravenous products due to its ability to grow in commercial infusion fluids [8-10].

Outbreaks in hospital are of special concern, not only due to the increased susceptibility of the patients to infections and complications [11], but also because of the additional burden placed on health care resources and the potential disruption of hospital services [12].

The objective of this study was to describe a nosocomial outbreak of Pantoea agglomerans and to explore risk factors for infection.

\section{Materials and Methods}

Outbreak

The "Santa Lúcia" Hospital is a 240-bed tertiary care hospital situated in Brasilia (DF). The pediatric emergency unit of this hospital ward has 8 beds available for hospitalization during more than 24 hours and 4 beds for hospitalization during less than 24 hours. The number of admitted children is on average 50 children per month. The most frequent procedures are intravenous rehydration and respiratory care.

On 04 August 2002, the infection control practitioner at Santa Lúcia Hospital was notified by the microbiology

Received on 16 July 2006; revised 5 March 2007.

Address for correspondence: Dr. Eliana L.Bicudo. SEPS 710/910. Ed Via Brasil - Torre B sala 536.Brasília DF. Zip code: 70390-180.Email:elianabicudo@brturbo.com.br.

The Brazilian Journal of Infectious Diseases 2007;11(2):281-284. (C) 2007 by The Brazilian Journal of Infectious Diseases and Contexto Publishing. All rights reserved. laboratory that there were 3 children hospitalized with positive blood cultures for Pantoea agglomerans and that the isolation of the same ones was simultaneous.

In response to these cases and after big quarrel with pediatrics, an investigation initiated.

We suspended the hospitalization in the pediatric intensive care unit and whoever needed intravenous therapy would go to another ward of the hospital, constituted by individual apartments.

\section{The Study Period}

A case-control study of patients hospitalized since 25 July until 06 August 2002 was conducted to examine risk factors for the acquisition of nosocomial infection caused by Pantoea agglomerans. The period in which the study was carried out had to be in the interval in which the casepatients had been hospitalized in our service until the sepsis be diagnosed and the suspension of the hospitalization.

The institutional review board of the Santa Lúcia Hospital has approved this study.

\section{Definition of Case and Control}

The case-patients were defined as the children hospitalized with positive blood cultures for Pantoea agglomerans. The control-patients were defined as children who were hospitalized, in this service, from 25 July until 6 August 2002 and did not have Pantoea agglomerans isolated from blood cultures or clinical picture of sepsis.

\section{Risk Factors}

Medical records were abstracted using a standardized data collection form. Information collected included each patient's age, gender, date of admission, location within the hospital, symptoms (vomiting, diarrhea or fever), and results of blood, urine and stool cultures at the time of the onset of symptoms. Potential risk factors for acquiring Pantoea agglomerans infections, such: number of solution compositions in the venous hydration, preparation room and medications were also recorded. 


\section{Environmental Investigation}

The preparation and dilution room records from routine and storage methods were observed by the hospital's infection control practitioners. We discovered that the solution compositions in the intravenous hydration, that were pediatric prescriptions, were carried with only one tube called transference tube: Aminomix (Figure 1). The routine was to keep transference tube connected with $\mathrm{NaCl} 0.9 \%$ solution (Figure 2) on the table until the next composition.

When we interviewed the nurses about practices related to transference tube changes, we did not have records.

\section{Microbiology}

Sample cultures were obtained from transference tube, sterile water passed through transference tube and $0.9 \%$ sodium chloride solution that was opened in the table preparation.

An inoculum of $10 \mathrm{~mL}$ of $0.9 \%$ sodium chloride solution and $10 \mathrm{~mL}$ of sterile water passed through transference equipment was plated on thioglycolate, blood and MacConkey agar plates. Plates were incubated at $37^{\circ} \mathrm{C}$ and observed for a period of 24 hours [13].

The transference tube fragment was plated with Maki rolling technique, on the same agar plates.

All Pantoea agglomerans clinical isolates were identified with the automated-method VITEK-GNI cards (bioMérieux Vitek, Hazelwood, MO).

Cultures were performed in the microbiology laboratory of the EXAME laboratory.

\section{Statistical Analysis}

Data were compiled and frequency distributions calculated with Epi Info software (version 6; CDC, Atlanta). Case-patients were compared with control-patients using the chi-square test.

\section{Results}

Six patients were identified with positive blood cultures for Pantoea agglomerans and have been admitted with diagnosis of sepsis (case-patients), and out of 15 patients that had been admitted in the period of the study only 10 (66.6\%) had received venous hydration and none had sepsis (control-patients).

The schedules of hospitalization, positive blood cultures and first composition of rehydration are in Figure 3.

All 6 case-patients infected with Pantoea agglomerans had gastrointestinal symptoms: vomiting (100\% versus $40 \%$ of the control-patients, $\mathrm{p}=0.003$ ) (Table 1 ). The presence of solution compositions in the intravenous rehydration received in bigger number than 2 compositions was a statistically significant predictor of Pantoea agglomerans sepsis (Table 1).

Gender and age did not differ significantly between casepatients and control-patients. Similar percentages of casepatients and control-patients had fever, diarrhea and days number of hospitalization.
Figure 1. Transference tube (Aminomix).

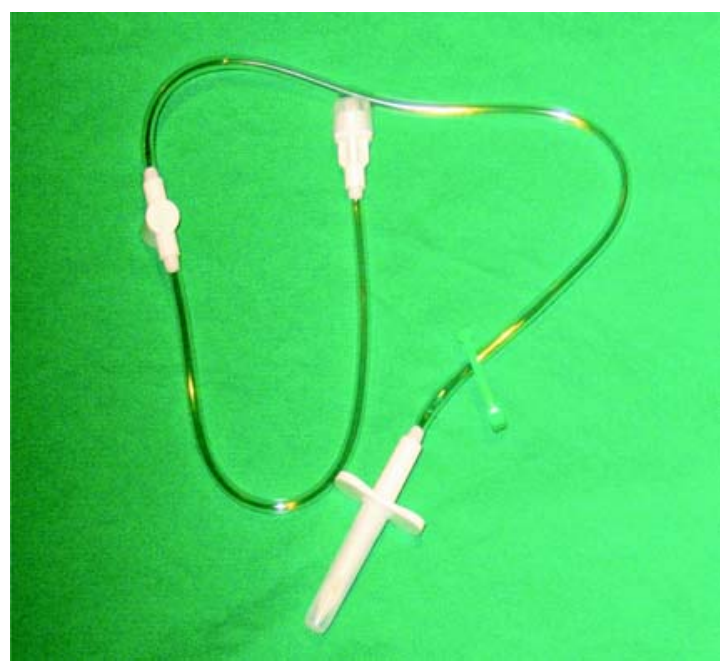

Figue 2. Transference tube connected with $\mathrm{NaCl} 0.9 \%$ solution.

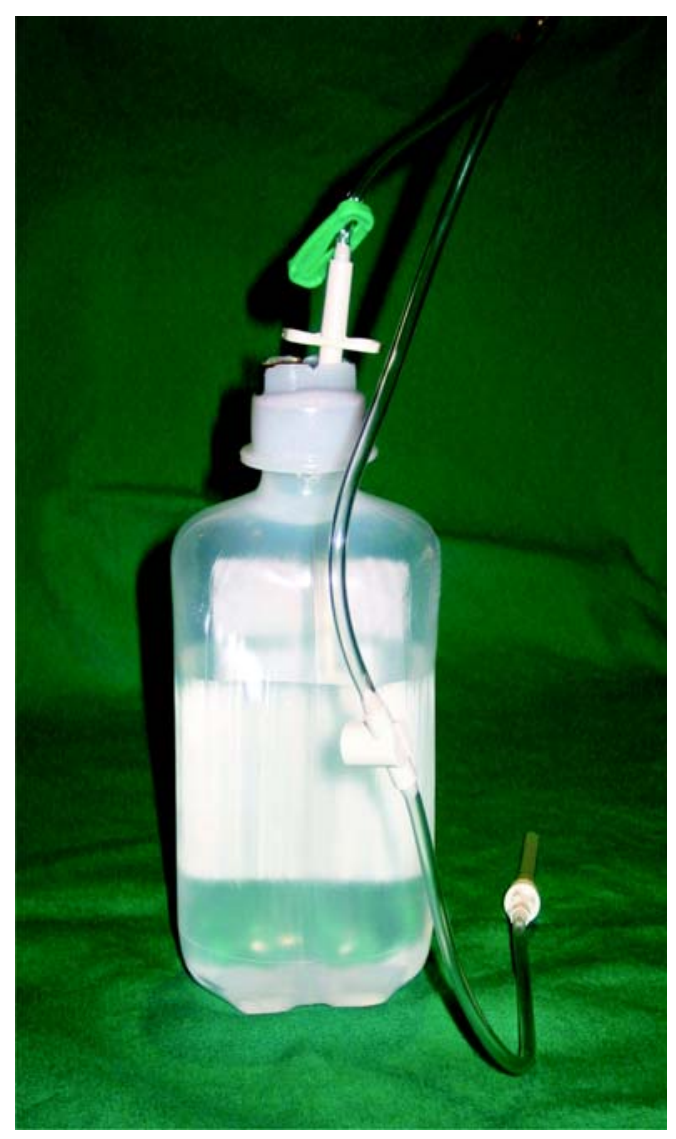

Microbiology laboratory recovered Pantoea agglomerans from samples of sterile water passed through transference tube and transference tube fragment.

We did not identify contaminated $0.9 \%$ sodium chloride solution.

All case-patients had received antimicrobials (ceftriaxone and amikacin) and the evolution of all the cases was favorable. 
Table 1. Demographic and clinical characteristics of case-patients infected with Pantoea agglomerans and control-patients

\begin{tabular}{lccr}
\hline Characteristics & $\begin{array}{c}\text { Casep patients } \\
\text { N/Total (\%) }\end{array}$ & $\begin{array}{c}\text { Control patients } \\
\text { N/Total (\%) }\end{array}$ & $\begin{array}{c}\text { P } \\
\boldsymbol{\chi}^{2}\end{array}$ \\
\hline Median age,y (range) & $4(3-5)$ & $3(1-5)$ & .26 \\
Male gender & $3 / 6(50)$ & $7 / 15(46.6)$ & .31 \\
Symptom or sign & & & .01 \\
$\quad$ Vomiting & $6 / 6(100)$ & $11 / 15(73.3)$ & .003 \\
$\quad$ Diarrhea & $5 / 6(83)$ & $12 / 15(40)$ & .38 \\
$\quad$ Fever & $5 / 6(83)$ & $10 / 15(66)$ & .004 \\
$\begin{array}{l}\text { Composition of rehydration } \\
\text { Median n }{ }^{\circ} \text {, composition of } \\
\text { rehydration (range) }\end{array}$ & $6 / 6(100)$ & $2(1-12)$ & .006 \\
$\begin{array}{l}\text { Median of total days of } \\
\text { hospitalization before sepsis (range) }\end{array}$ & $10(4-12)$ & $1(1-6)$ & .08 \\
\hline
\end{tabular}

Figure 3. Pantoea agglomerans infections by the dates. The schedules of first composition of rehydration and positive blood cultures.

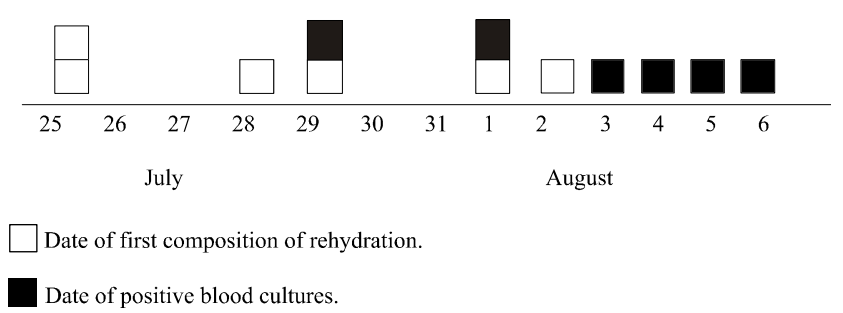

Following recognition of the outbreak infection, control practices were reviewed and reinforced with nurses and staff. All facilities discontinued use of transference tube for solution compositions. Another routine was created and when necessary, as in parenteral feeding preparation, it would be used only one.

\section{Discussion}

Since the beginning of this investigation, we characterized it as a nosocomial outbreak [14]. The outbreak definition is a particular form of epidemic, where 2 or more cases occurred, related between itself in time or in space, reaching a specific group of people, configuring clearly an excess of cases [15].

This outbreak had only 1 infectious agent, therefore 1 common source [16]. The children had been exposed to a common source of the Pantoea agglomerans, allowing the cases to appear in fast succession and in a short period of time.

We identified extrinsically contaminated transference tube used for rehydration as the source of this outbreak. A point source was confirmed after microbiology laboratory demonstrated strain relatedness among all case- patient isolates tested and Pantoea agglomerans isolates recovered from transference tube. After removal of the implicated product, no further cases were reported in the hospital.

Nosocomial outbreaks of Pantoea agglomerans rarely have been reported in the literature [5-7]. The results of this investigation suggested that the source of this outbreak was a transference tube and Pantoea agglomerans may have contaminated through the hands of staff members.

As a result of the outbreak, new policies were instituted in the preparation room aiming to improve cleaning and disinfection of the equipments and the environment. An alcohol-based hand sanitizer was placed in all inpatient units for use by staff, providing patient care. In addition, institution wide educational interventions emphasizing hand hygiene for the prevention of nosocomial diseases were implemented and, as part of this, the hospital staff was reminded that eating and drinking in patient care areas is prohibited. Increased emphasis on hand hygiene is an important measure of prevention. Additional resources should be targeted at optimizing and sustaining good hand hygiene among hospital staff.

This analysis implicated a transference tube used by the hospital as the source of an outbreak of nosocomial Pantoea agglomerans and this outbreak illustrated the importance of active hospital-based surveillance, including a close relationship between the infection control team and microbiology laboratory.

\section{References}

1. Abbott S.L.,Klebsiella,Enterobacter,Citrobacter, Serratia, Plesiomonas, and other Enterobacteriaceae. In: Murray P.R., Baron J., Tenover, F.C. \& Yolken, R.H. eds. Manual of clinical microbiology. 6.ed. Washington: American Society of Microbiology, 1995.

2. Laporte C., Demarchy M.C., Thevenin-Lemoine C. Tibial osteitis caused by Pantoea agglomerans after open grade IIIB tibial shaft fracture. Rev.Chir Orthop Reparatrice Appar Mot 2002;88(6):625-7.

3. Kratz A., Greenberg D., Barki Y., et al. Pantoea agglomerans as a cause of septic arthritis after palm tree thorn injury; case report and literature review. Archives of Disease in Childhood 2003;88:542-4. 
4. Fernandes A.T., Ribeiro N.F., Mazzano R.S., et al. Bactérias Aeróbias. In: Fernandes A.T., Fernandes M.O.V., Ribeiro N.F. Eds. Infecção Hospitalar e suas Interfaces na Área de Saúde. São Paulo: Editora Atheneu, 2000.

5. Burchard K.W., Barral D.T., Reed M., et al. Enterobacter bacteremia in surgical patients. Surgery 1986;100:857-61.

6. Chow J.W., Fine M.J., Shalaes D.M. Enterobacter bacteremia: clinical features and emergence of antibiotic resistance during therapy. Ann Intern Med 1991;115:585-90.

7. Gallagher P.G. Enterobacter bacteremia in Pediatric patients. Rev Infect Dis 1990;12:808-12.

8. Gonçalves C.R., Vaz T.M.I., Leite D., et al. Molecular Epidemiology of a nosocomial outbreak due to Enterobacter cloacae and Enterobacter agglomerans in Campinas, São Paulo, Brazil. Rev Inst Med Trop S Paulo 2000;41:1-21.

9. Maki D.G., Rhame F.S., Macckel D.C., et al. Nationwide epidemic of septicemia caused by contaminated intravenous products. Epidemiologic and clinical features. Amer. J. Med., 1976; 60:471-85.

10. Maki D.G., Martin W.T. Nationwide epidemic of septicemia caused by contaminated intravenous products. Growth of microbial pathogens in fluids for intravenous infusion. J Infect Dis 1975;131:267-72.
11. Spearing N.M., Jensen A., McCall B.J., et al. Direct costs associated with a nosocomial outbreak of Samonella infection: an ounce of prevention is worth a pound of cure. Am J Infect Control $2000 ; 28: 54-7$.

12. Bornemann R., Zerr D.M., Heath J., et al. An Outbreak of Salmonella Serotype Saintpaul in a children's hospital. Infection Control and Hospital Epidemiology 2002;23(11):671-6.

13. Wyant R., Moss C.W., Weaver R., et al. Identification of unusual pathogenic Gram-negative aerobic and facultative anaerobic bacteria. $2^{\text {nd }}$ ed. Baltimore: Williams \& Wilkins Press, 1996.

14. Garner J.S., Jarvis W.R., Emory T.G., et al. CDC definitions for nosocomial infections. Am $J$ Infect Control $1988 ; 16: 128-40$.

15. Fernandes A.T., Fernandes M.O.V. Investigação de Surtos hospitalares. In: Fernandes A.T., Fernandes M.O.V., Ribeiro N.F. Eds. Infecção Hospitalar e suas Interfaces na Área de Saúde. São Paulo: Editora Atheneu, 2000.

16. Gardner S., Shulman S.T. A nosocomial common source outbreak caused by Pseudomonas pickettii. Pediatric Infect Dis $1984 ; 3 ; 420-2$. 